\title{
Feeding Ecology, Food Availability and Ranging Patterns of Wild Hamadryas Baboons at Filoha
}

\author{
Amy L. Schreier \\ Duke University, Durham, N.C., USA
}

\section{Key Words}

Hamadryas baboons $\cdot$ Feeding ecology $\cdot$ Doum palm fruit $\cdot$ Phenology $\cdot$ Ranging patterns $\cdot$ Group size $\cdot$ Ethiopia

\begin{abstract}
Most hamadryas baboons rely on Acacia species for subsistence in their semidesert habitats. Unlike other hamadryas sites, palm forests at Filoha in Awash National Park, Ethiopia, provide the baboons with a preferred food resource close to a commonly used sleeping site. The baboons are expected to feed on doum palm trees when fruit is available, and this resource use should play a role in ranging patterns. This paper describes the feeding ecology, food availability and ranging patterns of a band of wild hamadryas baboons at Filoha from March 2005 to February 2006. Data on feeding and ranging behavior derive from band scans during all-day follows of baboons, and data on food availability derive from monthly phenological monitoring of frequently consumed food species. The baboons fed predominantly on palms when fruit was available, and preferred the flowers of Acacia senegal to its leaves. There was no relationship between daily path length and the proportion of palm fruit in the baboons' diet, but changes in the availability of fruit across the Filoha region appear to mirror the baboons' shifting use of its home range. The large band sizes at Filoha may obscure the effects doum palm fruit might have on ranging patterns.

Copyright $\odot 2010$ S. Karger AG, Basel
\end{abstract}

\section{Introduction}

Hamadryas baboons mainly live in semidesert habitats throughout the Horn of Africa (in parts of Ethiopia, Eritrea, Djibouti, Sudan and Somalia) and the Arabian Peninsula in Yemen and Saudi Arabia [Kummer, 1968; Kummer et al., 1981; Biquand

\begin{tabular}{ll}
\hline KARGER & (c) 2010 S. Karger AG, Basel \\
Fax +41 61 306 12 34 & \\
$\begin{array}{l}\text { E-Mail karger@karger.ch } \\
\text { www.karger.com }\end{array}$ & $\begin{array}{l}\text { Accessible online at: } \\
\text { www.karger.com/fpr }\end{array}$
\end{tabular}

Amy L. Schreier

Department of Evolutionary Anthropology

Duke University, Box 90383, Durham, NC 27708 (USA)

Tel. +1 919660 7281, Fax +19196607348

E-Mail amy.schreier@duke.edu 
et al., 1992; Al-Safadi, 1994; Zinner et al., 2001; Swedell, 2002b, 2006]. They are known to have among the longest daily path lengths of all primate species and a unique multi-level social organization in which large groups (bands) break into smaller foraging parties (1-male units and clans) during daily travel. These ranging and social patterns have often been attributed to the scarce and widely dispersed distribution of food resources in their habitats [Kummer, 1968, 1971, 1995; Sigg and Stolba, 1981; Dunbar, 1988; Swedell, 2002b, 2006].

The feeding patterns of a wide range of baboon populations have been quantified, and several studies have examined the relationships between dietary composition, ecological variables and activity patterns [Dunbar, 1992, 1996; Hill, 1999; Hill and Dunbar, 2002]. To date, however, there are few quantitative data on the feeding behavior of hamadryas baboons. Hamadryas rely on Acacia species (Mimosoideae) throughout their range [Nagel, 1973; Kummer, 1968; Kummer et al., 1981; Al-Safadi, 1994]. In Ethiopia, Nagel [1973] reported that hamadryas baboons at the Awash River most commonly fed on the flowers, seeds and fresh shoots of Acacia senegal, A. nubica, A. tortilis and A. clavigera, and appeared to prefer the flowers when they were available. At Erer Gota, Acacia species comprised the majority of the diet across seasons, and the baboons preferred Acacia flowers and grass seeds when they were available [Kummer, 1968]. Saudi Arabian hamadryas populations also fed primarily on Acacia trees and other semidesert plants such as Grewia spp. and Dobera glabra [Kummer et al., 1981; Al-Safadi, 1994].

In this paper, I describe the feeding behavior of a band of wild hamadryas baboons at the Filoha site in Awash National Park in Central Ethiopia as well as the relationship between food availability and ranging patterns. The home ranges of the Filoha baboons consist of Acacia scrublands, open grasslands and cliffs, all of which are typical of hamadryas habitat in other parts of their geographic range [Kummer, 1968; Sigg and Stolba, 1981; Biquand et al., 1992; Al-Safadi, 1994; Zinner et al., 2001; Swedell, 2006]. Unlike many other areas inhabited by hamadryas baboons, however, the Filoha area also contains palm forests, hot springs and swamp vegetation [Swedell, 2002b, 2006]. These habitat types provide the baboons with food and water resources typically unavailable elsewhere in their range, namely a high availability of doum palm fruit (Hyphaene thebaica, Arecaceae).

A recent study focusing on band 3 at Filoha showed that doum palm fruit is a major component of the baboons' diet [Swedell et al., 2008]. In particular, they spent almost half of their feeding time (47.4\%) eating $H$. thebaica and $11.6 \%$ of feeding time on A. senegal; no other food species contributed more than $6.2 \%$ to the baboons' total feeding time. The baboons relied more heavily on $H$. thebaica during the dry season than the wet season, but data were not available to examine this seasonal pattern with respect to the abundance of palm fruit over the course of the study period [Swedell et al., 2008]. The overall consumption of $A$. senegal did not vary seasonally; the baboons consumed the seeds, flowers, leaves and gum, but results did not indicate which of these plant parts the baboons focused on at particular times of the year and how this related to the patterns of flowering and leafing in their home range. Furthermore, corresponding data on ranging were not collected, and thus the relationship between feeding ecology and ranging patterns could not be assessed.

The band and clan sizes in the Filoha population of hamadryas baboons are larger than those described for other populations (Erer Gota, Ethiopia [Kummer, 1968; Sigg and Stolba, 1981; Abegglen, 1984]; Awash River, Ethiopia [Nagel, 1973]; 
Saudi Arabia [Kummer et al., 1981; Biquand et al., 1992]; Yemen [Al-Safadi, 1994]), and this has been attributed to the high availability of doum palm fruit at Filoha [Swedell, 2002b, 2006]. Despite the apparent abundance of food resources at Filoha (i.e. the presence of doum palms) compared to other areas inhabited by hamadryas baboons, periods of relative food scarcity appear to underlie band fissions into clans for extended periods; the band foraged as 2 independent clans for an entire month when palm fruit was not available [Schreier and Swedell, 2009]. The presence of doum palm fruit at Filoha has an impact on the size of hamadryas subgroupings, and thus it may also play a role in determining the baboons' ranging patterns.

Here I use an expanded data set to confirm the dietary patterns described by Swedell et al. [2008] at Filoha and relate them to the phenology of the most frequently consumed food species. Furthermore, I examine the relationship between the availability and consumption of doum palm fruit and $A$. senegal on hamadryas ranging patterns. Namely, I expect the contribution of $H$. thebaica to the baboons' feeding at Filoha to be related to the abundance of its fruit throughout the band's home range. I expect the baboons to feed on the flowers and seeds of $A$. senegal when available and to rely on leaves only when the higher-quality parts are not available. Due to the accessibility of doum palm fruit in close proximity to a commonly used sleeping site, I predict that daily path lengths will be shorter than those at other hamadryas sites. I also expect an inverse relationship between daily path length and the proportion of palm fruit in the baboons' diet because the baboons at Filoha do not need to travel long distances to obtain this important food resource. Because of the large band sizes at Filoha, I also discuss associations between feeding ecology, ranging behavior and group size.

\section{Methods}

Study Site and Subjects

This study took place at the Filoha outpost of Awash National Park, Ethiopia $\left(9^{\circ} 6^{\prime} 27^{\prime \prime} \mathrm{N}\right.$, $40^{\circ} 0^{\prime} 50^{\prime \prime} \mathrm{E}$ ) from March 5, 2005, to February 17, 2006. The outpost is surrounded by about $2 \mathrm{~km}^{2}$ of natural hot springs, doum palm trees, swamp vegetation and a $1.5 \mathrm{~km}$-long cliff [Swedell, 2002b, 2006]. The Awash region typically receives two periods of rainfall. The long rains occur between June and September, and the short rains fall intermittently between February and May [Swedell, 2006]. Total rainfall during the study period was $606.7 \mathrm{~mm}$, almost half of which occurred during the wet season of July and August.

Several bands of hamadryas baboons populate the Filoha region. The study group - band 1 - has been the focus of studies intermittently since 1996 (previously called 'group 1' [Swedell, 2002a, b; Swedell and Tesfaye, 2003; Swedell, 2006; Schreier and Swedell, 2008, 2009]. In February 2006, band 1 consisted of approximately 210 individuals, including 24 leader males, 7 follower males, about 20 adult and subadult solitary males, 53 adult females, 13 subadult females and at least 90 juveniles and infants.

\section{Data Collection and Analyses}

Habitat and Phenology

The Filoha region consists of 5 habitat types: Acacia scrublands, palm forests, open grasslands, swamp vegetation and cliffs (fig. 1). To describe the distribution of food resources in the home range of band 1 , I conducted vegetation transects $(50 \times 4 \mathrm{~m})$ in 4 of these habitat types [Schreier, 2009]; a subset of the Acacia scrubland and palm forest transects was used for phenological monitoring (see below). Because cliffs have no (or very little) vegetation, no transects were carried out on cliffs. There are at least 4 cliffs in the Filoha vicinity (fig. 1), although the 


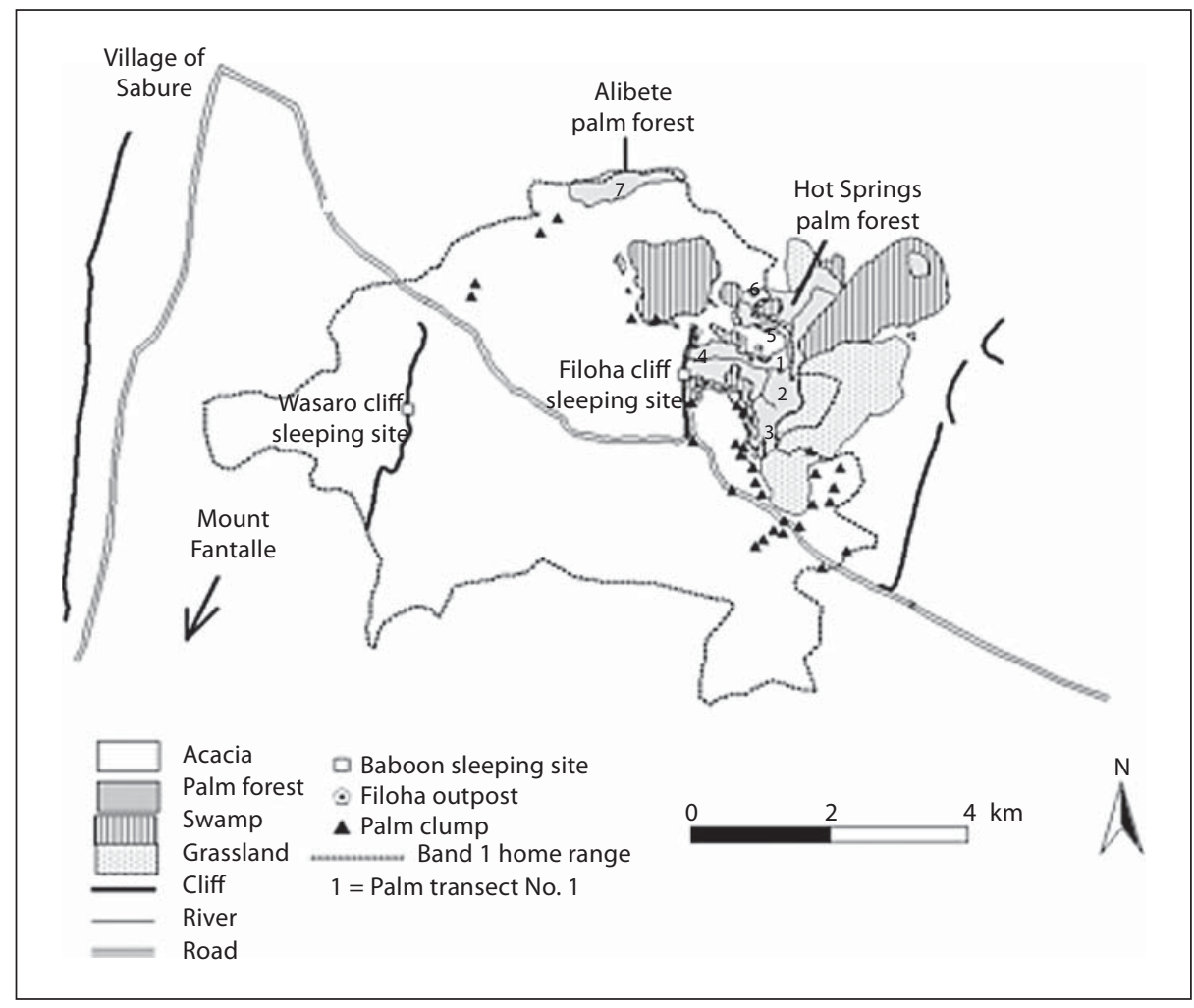

Fig. 1. Map of Filoha region, including palm forest transects.

baboons predominantly slept on 2: the Filoha cliff (about $200 \mathrm{~m}$ from camp) and the Wasaro cliff (about $4 \mathrm{~km}$ west of Filoha).

In January and July 2004, I learned to recognize and identify the plant species in the baboons' home range from G. Hailemeskel of the Ethiopian Wildlife Conservation Department. While I had originally intended to sample the abundance of plant parts of the most frequently eaten species (based on the previous study by Swedell et al. [2008]) bimonthly in each vegetation transect, this was not possible due to the prohibitively large size of the home range of band 1 (at least $38.6 \mathrm{~km}^{2}$ [Schreier, 2009]). Therefore, I monitored the phenology of the 2 most frequently consumed food species by the baboons - A. senegal and $H$. thebaica - in patches in which band 1 regularly foraged.

I sampled the abundance of fresh leaves, seed pods and flowers for A. senegal monthly in 6 transects spread throughout the band's home range corresponding with high use by the baboons: transect 1 , just west of the Filoha cliff sleeping site; transect 5 , south of the Filoha camp and just north of the road; transect 13, about $2 \mathrm{~km}$ northwest of the Filoha cliff sleeping site; transect 17, about $2 \mathrm{~km}$ southwest of the Filoha cliff; transect 18, just east of the Wasaro cliff sleeping site, and transect 19, west of the Wasaro cliff (fig. 2). I began systematically monitoring A. senegal in April 2005. I estimated the presence of fresh leaves, seed pods and flowers on each tree on a scale from 1 to $4(1=0-25 \%$ coverage; $2=26-50 \%$ coverage; $3=51-75 \%$ coverage; $4=$ 76-100\% coverage) [Chapman et al., 1994; Peres, 1994; Cunningham, 2003].

I sampled the abundance of ripe doum palm fruit (H. thebaica) in 4 palm patches: transect 1, about $1 \mathrm{~km}$ east of the Filoha cliff sleeping site; transect 3, about $2 \mathrm{~km}$ southeast of the Filoha 


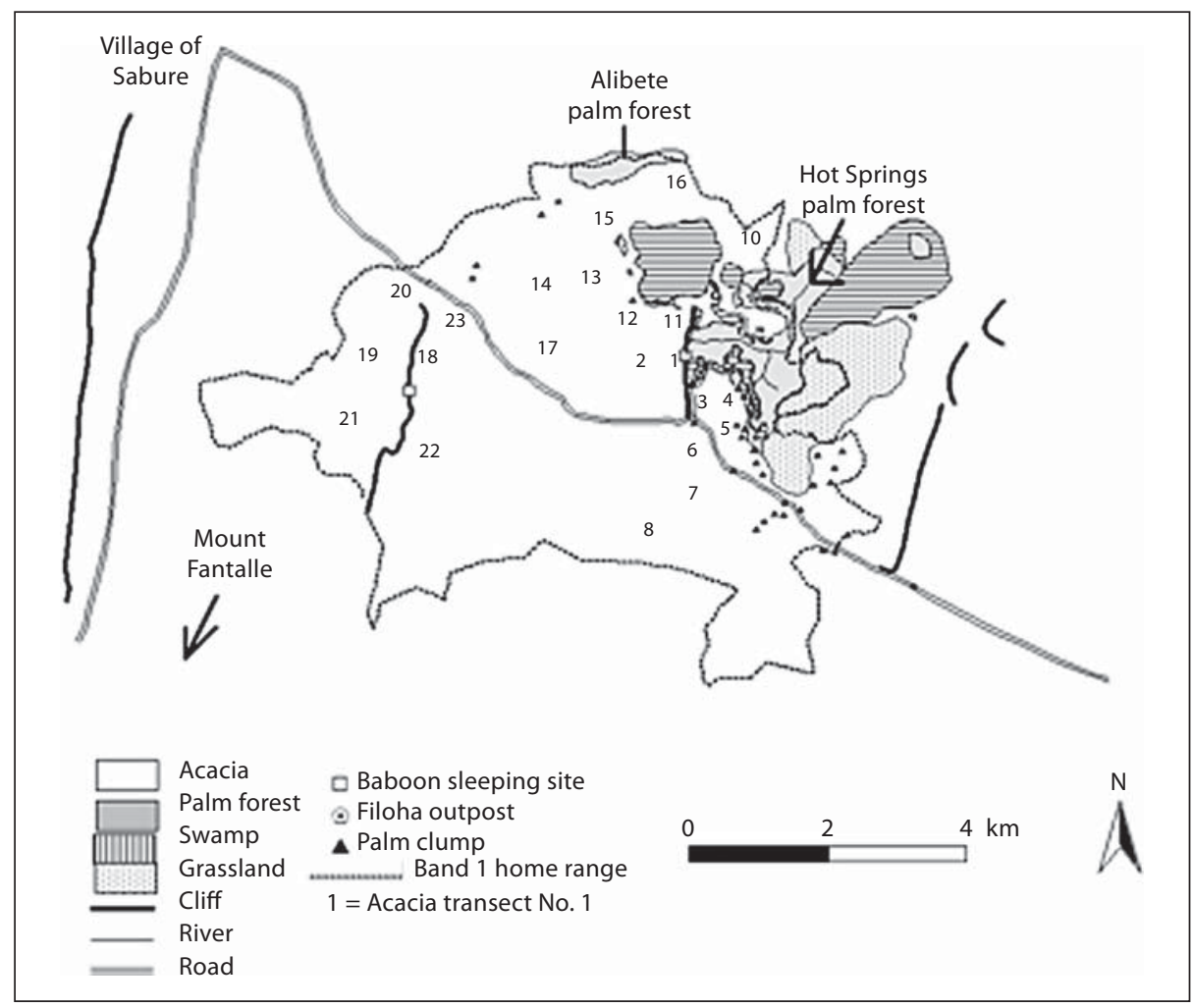

Fig. 2. Map of Filoha region showing Acacia scrubland transects.

cliff sleeping site; transect 5, about $1.5 \mathrm{~km}$ northeast of the sleeping site in the Hot Springs palm forest, and transect 7 in the Alibete palm forest (fig. 1). Band 1 first traveled to and fed from the palm clumps in Acacia scrublands southeast of Filoha in June 2005, and I monitored the abundance of fruit there for the remainder of the study period. Doum palm fruit occurs in bunches, and I estimated the abundance of ripe fruit on a scale from 1 to 4 based on the percentage of bunches that bore ripe fruit $(1=$ bunches $0-25 \%$ full; $2=$ bunches $26-50 \%$ full; $3=$ bunches $51-75 \%$ full; 4 = bunches $76-100 \%$ full). Ripe fruit is orange in color and has a softer exterior than unripe fruit, which is more purple in color. I monitored the abundance of palm fruit from the onset of the study period in March 2005 for transects 1, 5 and 7, but I did not score abundance in transect 3 until April.

\section{Behavioral Sampling}

Behavioral data were collected during all-day follows of band 1. Accompanied by a field assistant, I located the baboons at their sleeping cliff at $6.00 \mathrm{~h}$ and followed them until $18.00 \mathrm{~h}$, or for as long as possible until we had to leave them to return to camp before dark. Every $15 \mathrm{~min}$, I conducted an instantaneous scan sample during which I recorded food items at the species level, as well as the plant parts being eaten, when adult members of band 1 were feeding. Feeding was defined as all food handling and processing. Due to the large band size and visibility restrictions, I could not sample all adult members of the band during each scan. Therefore, a food species was recorded just once regardless of how many individuals were feeding on it, as opposed to recording the foods being fed on by every visible baboon. If the baboons fed on more 
Table 1. Feeding records and mean daily path lengths by month

\begin{tabular}{lccc}
\hline Month & $\begin{array}{l}\text { Feeding } \\
\text { records }\end{array}$ & $\begin{array}{l}\text { Observation } \\
\text { days }\end{array}$ & $\begin{array}{l}\text { Mean daily } \\
\text { path length, km }\end{array}$ \\
\hline March 2005 & 95 & 19 & $9.7(8)$ \\
April 2005 & 357 & 19 & $8.7(16)$ \\
May 2005 & 447 & 15 & $9.3(12)$ \\
June 2005 & 347 & 13 & $9.3(11)$ \\
July 2005 & 294 & 10 & $11.0(6)$ \\
August 2005 & 315 & 10 & $7.3(9)$ \\
October 2005 & 299 & 9 & $6.0(8)$ \\
November 2005 & 352 & 11 & $7.5(7)$ \\
December 2005 & 626 & 17 & $8.4(14)$ \\
January 2006 & 364 & 13 & $7.1(6)$ \\
February 2006 & 213 & 10 & $8.3(105)$ \\
\hline Total & 3,669 & 155 & \\
\hline
\end{tabular}

Figures in parentheses indicate numbers of daily paths.

than one food species during a given scan, they were counted as separate feeding records. When members of the band were feeding on different plant parts of a particular species during a scan, I noted each plant part.

Because the number of feeding records varied widely across months (table 1), I calculated monthly feeding budgets as proportions of the total number of feeding records for each month. The annual feeding budget represents the average of the monthly feeding budgets. While the baboons consumed just the fruit of $H$. thebaica, they consumed more than one plant part for $A$. senegal and Tribulus cistoides (Zygophyllaceae), the third most frequently consumed food species (see below), and I therefore calculated the consumption of different plant parts of these 2 species each month as a proportion of the total number of feeding records of each species for which I had data on a plant part consumed.

During all-day follows, I mapped the geographic center of the band every $15 \mathrm{~min}$ [Sigg and Stolba, 1981] using a Garmin etrex Legend handheld Global Positioning System unit. Ranging patterns were determined based on observation days for which I recorded complete travel routes (i.e. from the morning sleeping site to the evening sleeping site) [Altmann and Altmann, 1970; Sigg and Stolba, 1981]. I computed daily path lengths by summing the distance between all mapped locations. On days when I had to leave the baboons before they arrived at the Wasaro cliff (in order to return to camp by dark), I calculated the straight distance from where I left the baboons to their usual Wasaro cliff sleeping site (confirming this location the following morning). As the baboons most likely did not travel directly to their sleeping site, these daily path lengths represent minimum distances traveled. I analyzed daily paths using Arc View GIS 3.1 software.

I performed Spearman rank order correlations between monthly contribution of $H$. thebaica and $A$. senegal to feeding, the monthly abundance of palm fruit and A. senegal flowers, seeds and leaves, and monthly mean daily path lengths to investigate the relationships between feeding behavior, food availability and ranging patterns. The band separated into 2 independent subgroups for 31 consecutive days in September-October 2005. Data from this time period were not included in these analyses so that the differences in group size would not confound results (and thus no data are included for September). 
Table 2. Composition of band 1 annual feeding budget by species

\begin{tabular}{|c|c|c|c|c|}
\hline Family & Species & Parts eaten & $\begin{array}{l}\text { Annual } \\
\text { feeding budget } \\
\%\end{array}$ & $\begin{array}{l}\text { Months } \\
\text { consumed } \\
\mathrm{n}\end{array}$ \\
\hline \multirow[t]{2}{*}{ Acanthaceae } & Barleria spinisepala & $\mathrm{L}, \mathrm{Se}$ & 1.0 & 6 \\
\hline & Justicia odora & $\mathrm{L}$ & 0.0 & 1 \\
\hline Aloeaceae & Aloe spp. & Rs & 0.1 & 2 \\
\hline \multirow[t]{2}{*}{ Amaranthaceae } & Psilotrichum gnaphalobryum & $\mathrm{L}, \mathrm{Se}$ & 1.7 & 5 \\
\hline & Pupalia lappacea & $\mathrm{Fl}, \mathrm{L}$ & 0.2 & 5 \\
\hline Apparidaceae & Godoba rotundifolia & $\mathrm{L}, \mathrm{Se}$ & 0.8 & 9 \\
\hline Arecaceae & Hyphaene thebaica & $\mathrm{Fr}$ & 21.2 & 10 \\
\hline \multirow[t]{2}{*}{ Asclepiadaceae } & Pentarrhinum insipidum & $\mathrm{Fl}, \mathrm{L}$ & 4.5 & 11 \\
\hline & Sarcostemma viminale & $\mathrm{La}$ & 0.4 & 3 \\
\hline Balanitaceae & Balanites aegyptiaca & Fr, L, Se & 1.7 & 8 \\
\hline Boraginaceae & Heliotropium strigosum & $\mathrm{Fl}, \mathrm{L}$ & 0.2 & 1 \\
\hline Cactaceae & Cactus spp. & $\mathrm{R}$ & 0.0 & 1 \\
\hline Caesalpinioideae & Delonix elata & $\mathrm{Se}$ & 0.0 & 1 \\
\hline \multirow[t]{2}{*}{ Convolvulaceae } & Seddera bagshawei & $\mathrm{L}, \mathrm{Se}$ & 1.8 & 9 \\
\hline & Seddera latifolia & $\mathrm{L}$ & 0.1 & 2 \\
\hline Cyperaceae & Cyperus rotundus & $\mathrm{Bl}, \mathrm{Fl}, \mathrm{R}, \mathrm{St}$ & 1.4 & 9 \\
\hline Lamiaceae & Ocimum americanum & $\mathrm{L}, \mathrm{R}, \mathrm{Se}, \mathrm{St}$ & 0.2 & 3 \\
\hline \multirow[t]{5}{*}{ Mimosoideae } & Acacia mellifera & $\mathrm{L}, \mathrm{Fl}, \mathrm{Se}$ & 2.8 & 11 \\
\hline & Acacia nilotica & $\mathrm{Se}$ & 0.7 & 10 \\
\hline & Acacia nubica & $\mathrm{L}, \mathrm{Fl}, \mathrm{Se}$ & 7.6 & 10 \\
\hline & Acacia senegal & $\mathrm{G}, \mathrm{L}, \mathrm{Fl}, \mathrm{Se}$ & 23.5 & 11 \\
\hline & Acacia tortilis & $\mathrm{G}, \mathrm{L}, \mathrm{Fl}, \mathrm{Se}$ & 4.4 & 11 \\
\hline \multirow[t]{5}{*}{ Poaceae } & Coelachyrum poiflorum & $\mathrm{Bl}$ & 0.0 & 1 \\
\hline & Chrysopogon plumulosus & $\mathrm{R}$ & 0.1 & 1 \\
\hline & Sporobolus consimilis & $\mathrm{Bl}, \mathrm{Fl}, \mathrm{R}, \mathrm{St}$ & 0.9 & 8 \\
\hline & Sporobolus ioclados & $\mathrm{Bl}, \mathrm{Fl}, \mathrm{R}, \mathrm{St}$ & 0.5 & 7 \\
\hline & Sporobolus spicatus & $\mathrm{Bl}, \mathrm{Fl}, \mathrm{R}, \mathrm{St}$ & 2.1 & 9 \\
\hline Salvadoraceae & Salvadora persica & Fl, Fr, L & 1.8 & 8 \\
\hline \multirow[t]{3}{*}{ Tiliaceae } & Grewia erythreae & Fr, L, Se & 1.1 & 7 \\
\hline & Grewia tenax & $\mathrm{Se}$ & 0.1 & 2 \\
\hline & Grewia villosa & Fr, L & 0.1 & 4 \\
\hline Typhaceae & Typha latifolia & $\mathrm{RS}, \mathrm{St}$ & 2.2 & 9 \\
\hline Verbenaceae & Chaseanum laetum & $\mathrm{L}$ & 0.1 & 1 \\
\hline Zygophyllaceae & Tribulus cistoides & $\mathrm{Fl}, \mathrm{L}, \mathrm{Se}$ & 10.1 & 11 \\
\hline \multirow[t]{5}{*}{ Unidentified } & unidentified 1 & $\mathrm{Bl}, \mathrm{R}$ & 0.4 & 4 \\
\hline & unidentified 2 & $\mathrm{~L}, \mathrm{Se}$ & 0.3 & 2 \\
\hline & unidentified 3 & $\mathrm{~L}, \mathrm{Fl}$ & 0.4 & 2 \\
\hline & unidentified 4 & $\mathrm{~L}$ & 0.0 & 2 \\
\hline & unidentified 5 & $\mathrm{~L}, \mathrm{Fl}$ & 0.1 & 1 \\
\hline
\end{tabular}

$\mathrm{Bl}=$ Blades; $\mathrm{Fr}=$ fruit $\mathrm{Fl}=$ flowers $\mathrm{G}=$ gum; $\mathrm{L}=$ leaves; $\mathrm{La}=$ latex; $\mathrm{R}=$ roots; $\mathrm{RS}=$ root sheath; $\mathrm{Se}=$ seeds; $\mathrm{St}=$ stems. Months of consumption out of a total of 11 months (September not included in annual diet because no data on band 1 in its entirety). 


\section{Results}

Annual Feeding Habits

The baboons were observed feeding from 40 species of plants belonging to at least 27 genera and 20 families (table 2). Although the baboons ate a variety of species, only 16 plant species each contributed at least $1 \%$ of the annual feeding budget. The top 3 plant species comprised over half (54.8\%) of the annual feeding budget of band 1 . The baboons fed most frequently on the seeds, leaves and flowers of $A$. senegal (23.5\%) and doum palm fruit (H. thebaica; 21.2\%). The flowers, leaves and seeds of T. cistoides comprised at least $10.1 \%$ of its feeding budget, and no other plant species contributed more than $8 \%$ of the feeding budget.

\section{Phenology}

Overall, $H$. thebaica is distributed in large clumps, while Acacia spp. are more widely dispersed. Within each of the 6 Acacia scrubland transects, the abundance scores of each tree were averaged (since they were almost always the same) to provide 1 score for each plant part per month. The average scores across transects were also almost always the same, and results are therefore presented as an average of all 6 transects [for complete results of vegetation transects and phenology scores, see Schreier, 2009]. Leaves were the most abundant $A$. senegal part over the study period (fig. 3a). A. senegal trees were completely covered with fresh leaves during and just after the wet season in July, August and September. A. senegal flowers were available only in April and August, following high amounts of rainfall (fig. 3b). Seed pods never received an abundance score over 2 (fig. 3c).

Palm fruit phenology is also presented as an average abundance score for each transect per month. While the same general pattern of fruiting was consistent across palm forest transects, average abundance scores did differ during 4 months, and they are therefore presented separately for each of the 4 transects (fig. 4). Overall, the abundance of ripe palm fruit was highest at the beginning of the study period and then declined to very low levels by July. Ripe fruit abundance then increased in the last few months of the study period. By contrast, the palm clumps in Acacia scrublands southeast of Filoha (fig. 1) had average abundance scores of between 2.8 and 3.5 from June through December when the abundance of ripe palm fruit in the palm forests was low (fig. 4).

\section{Temporal Patterning of Feeding Behavior}

The inclusion of the 16 plant species that contributed at least $1 \%$ of the annual feeding budget of band 1 was variable on a monthly basis (table 3). Of the 3 most frequently consumed species, $A$. senegal contributed at least $15 \%$ to the feeding records each month. H. thebaica made up at least $20 \%$ of the feeding records during 7 months and was the most frequently eaten species during 6 of them. It did not, however, contribute more than $8 \%$ of the feeding records in the remaining 4 months, and the baboons were not observed eating doum palm fruit during August, the peak of the wet season. T. cistoides contributed less than $6 \%$ of the feeding records in 8 months but comprised at least $59.4 \%$ of the feeding in August, a substantially higher percentage than any other plant species' contribution to any month's feeding records.

The consumption of $H$. thebaica was coupled with the abundance of its fruit. The proportion of $H$. thebaica in the feeding records was positively related to the 

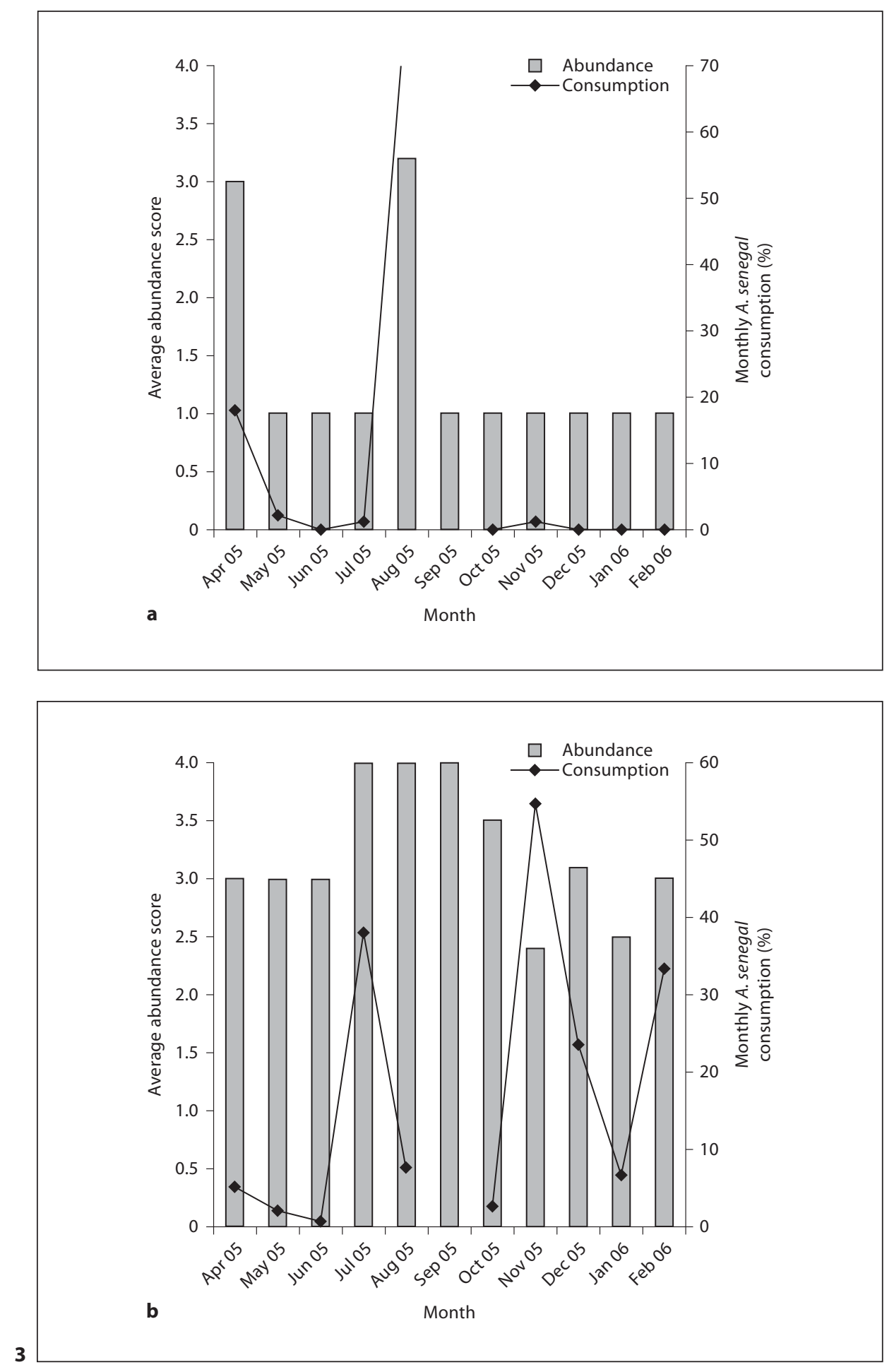

Feeding and Ranging Behavior of Hamadryas

Folia Primatol 2010;81:129-145 


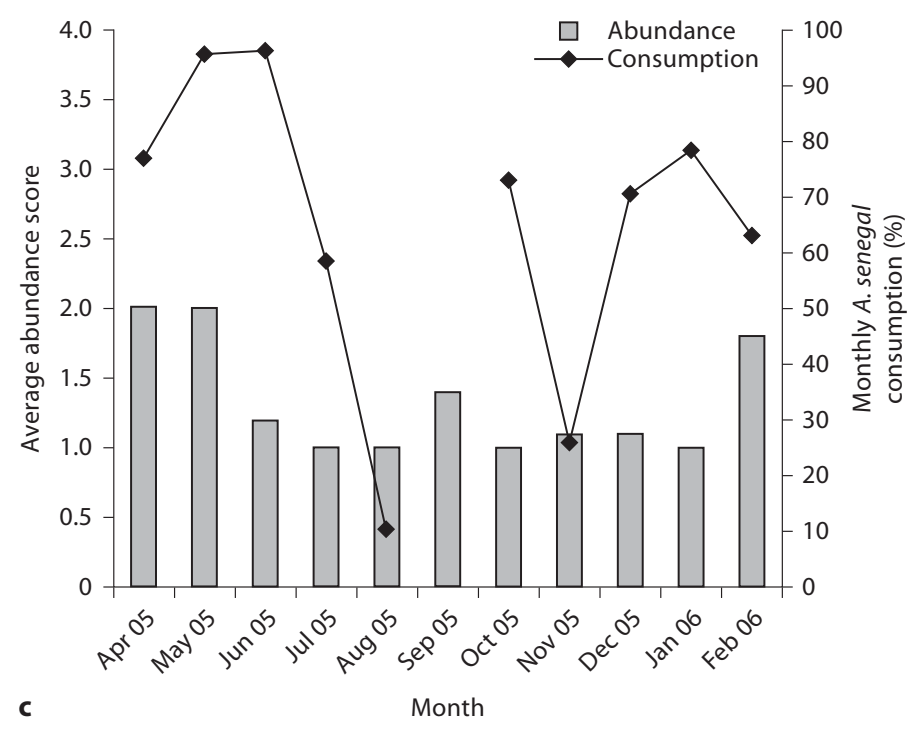

Fig. 3. Monthly consumption and abundance of $A$. senegal plant parts. a Flowers: flowers made up over $60 \%$ of $A$. senegal consumption when its abundance peaked in August. b Leaves: leaves were the most abundant $A$. senegal part over the study period, but the baboons fed on them only when other plant parts were not available. c Seeds: seeds contributed at least $50 \%$ to A. senegal consumption in 8 months even though seed pods never received an abundance score over 2 . This can be attributed partly to the fact that in June, July and October the baboons fed predominantly on dry seeds beneath trees (when trees were essentially devoid of seed pods), which were not included in phenological sampling.

overall abundance of doum palm fruit in palm forests, but this relationship was not statistically significant $\left(\mathrm{r}_{\mathrm{s}}=0.532, \mathrm{p}=0.075, \mathrm{n}=12\right)$. Positive relationships existed between the contribution of $H$. thebaica to feeding records in all 4 patches in which abundance was monitored, but only that of transect 1 was statistically significant $\left(\mathrm{r}_{\mathrm{s}}=0.919, \mathrm{p}=0.000, \mathrm{n}=10\right)$.

The baboons fed on several plant parts of $A$. senegal, and this consumption varied across months. The baboons' consumption of $A$. senegal flowers was positively related to their abundance in the home range of band $1\left(\mathrm{r}_{\mathrm{s}}=0.747, \mathrm{p}=0.013, \mathrm{n}=10\right)$. Flowers made up over $60 \%$ of the baboons' consumption of $A$. senegal in August when their average abundance peaked at over 3; during the rest of the year - with the exception of April - the abundance of flowers was low and the baboons fed on other plant parts (fig. 3a). There was no relationship between the consumption of $A$. senegal leaves and their abundance; while leaf abundance was relatively high throughout the study 


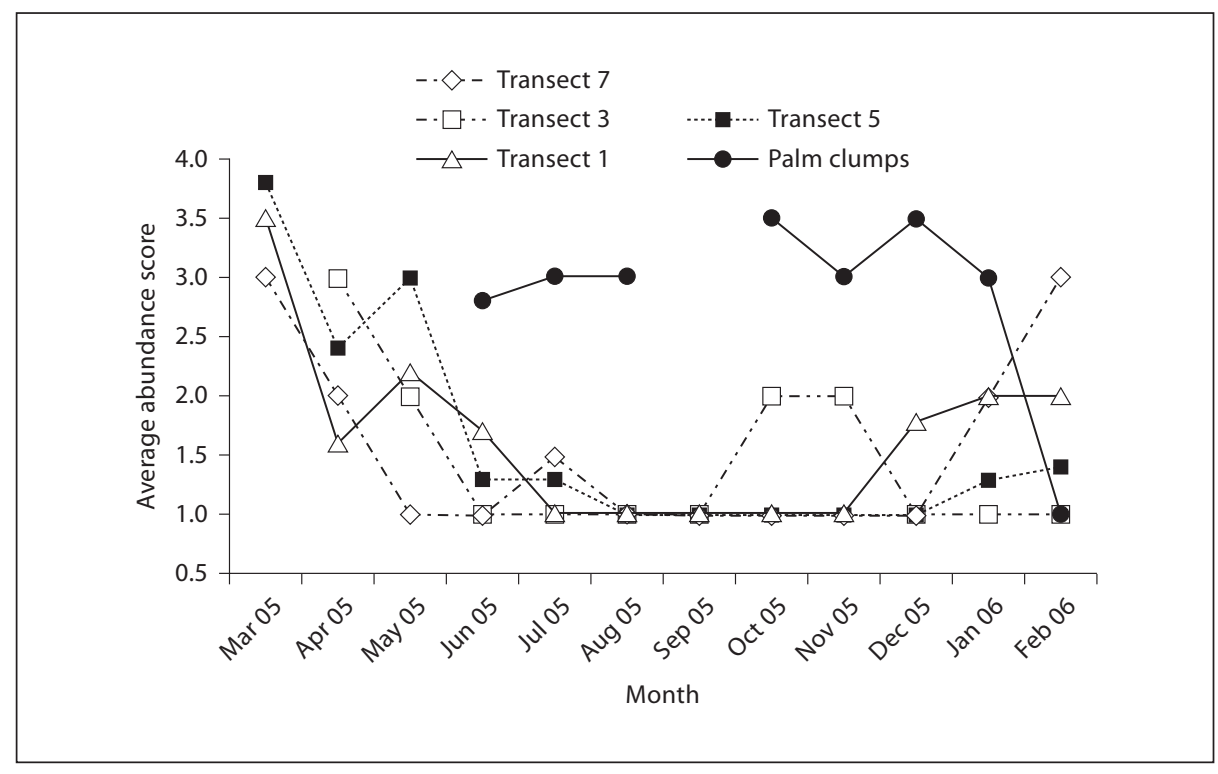

Fig. 4. Average abundance of ripe doum palm fruit in palm forests and clumps. The abundance of palm fruit in palm forests (i.e. transects 1, 3, 5, 7) was highest in March, April and May and declined to very low levels in June. Fruit abundance increased in the last few months of the study period. When the abundance of ripe fruit in palm forests was low in June to December, the baboons fed on palm fruit from palm clumps in Acacia scrublands southeast of Filoha where abundance ranged from 2.8 to 3.5 during these months.

period (fig. 3b), the baboons appeared to feed on them only when other plant parts were not available. The baboons' preference for young (vs. mature) leaves was indicated by the fact that $A$. senegal leaves were consumed most frequently in November, when during the last week of the month after 2 days of rain (the only rain in 2 months) A. senegal young leaves were abundant and the flowers not available, as well as in July when leaves were fresh (and flowers not yet abundant). There was also no clear relationship between the consumption of $A$. senegal seeds and their abundance (fig. $3 c$ ). This can be attributed to the fact that in June, July and October the baboons fed predominantly on dry seeds from the ground underneath shrubs; during these months, trees were essentially devoid of seed pods, but dry seeds covered much of the area beneath the trees; I did not quantify the abundance of plant parts underneath trees, and the abundance scores for seed pods are therefore misleading for these periods.

The temporal patterns of the consumption of the different parts of T. cistoides were more extreme than those of $A$. senegal. The baboons fed only on the leaves in May and June, and only on the seeds from October to February. In July, flowers made up $45.6 \%$ of the total T. cistoides feeding records $(n=57)$, and in August, when $T$. cistoides contributed $60 \%$ of the monthly feeding records, flowers comprised $92.6 \%$ of T. cistoides feeding $(\mathrm{n}=189)$. The phenological patterns of T. cistoides were not systematically quantified, but qualitative observations suggest a high correspondence between its flowering patterns and that of A. senegal. Namely, the flowers of 

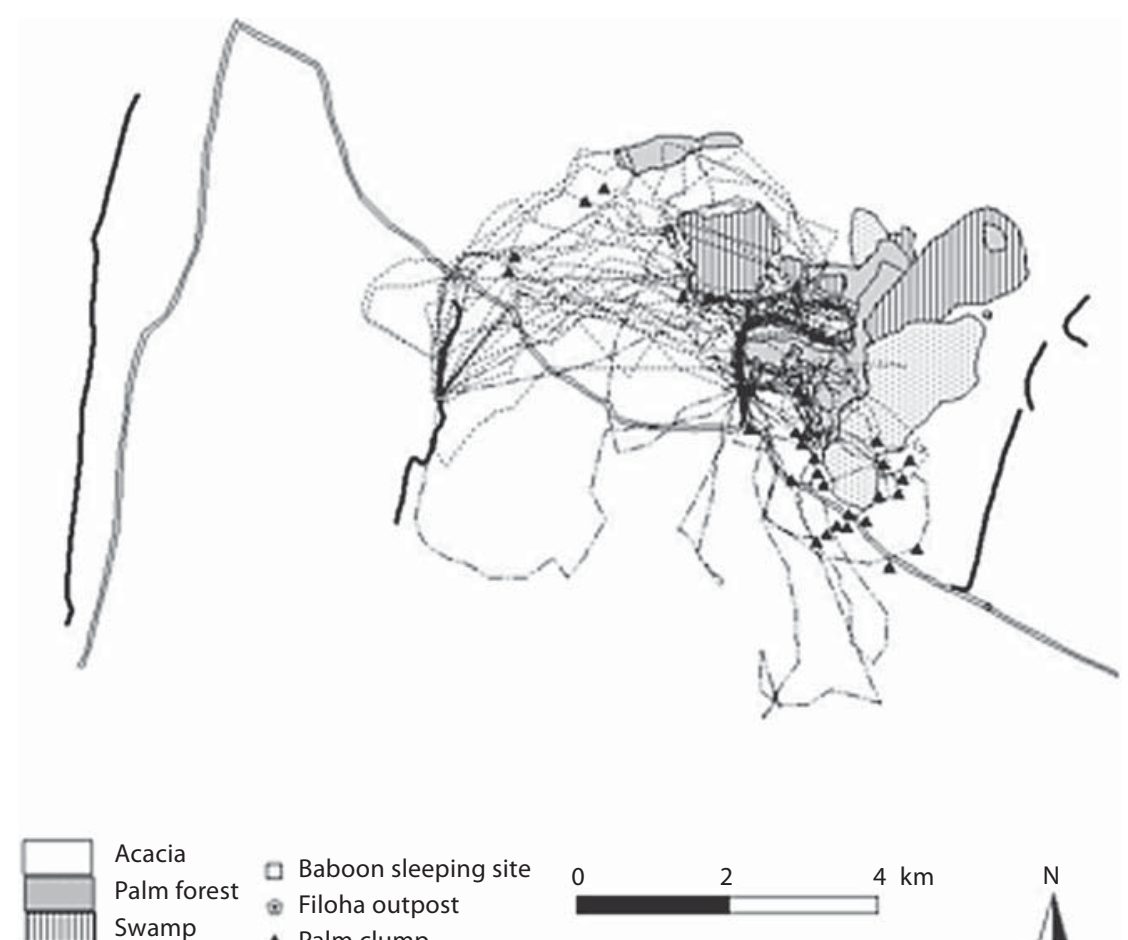

a Baboon sleeping site 0

( ) Filoha outpost

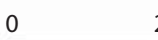

2

Grassland

A Palm clump

Cliff

River

March, April, May travel routes

Road

June travel routes

Fig. 5. Daily paths in March, April and May $(n=36)$ compared to June $(n=11)$. The baboons' home range use reflected where they fed on palm fruit. In March, April and May, the baboons fed on palm fruit most commonly from the Hot Springs and Alibete palm forests. In mid-June when ripe fruit was no longer available in the palm forests, the baboons shifted their use of the home range to the south and fed on fruit from palm clumps southeast of Filoha where ripe fruit was abundant.

T. cistoides were available throughout the home range of band 1 during August; during other months of the year, leaves and/or seeds were available, but not flowers, indicating a high correspondence between the consumption of the flowers and their availability.

\section{Ranging Behavior}

The mean daily path length of band 1 was $8.3 \mathrm{~km}( \pm 2.04, \mathrm{n}=105$; range $=4.6-$ $14.2 \mathrm{~km}$; see fig. 5 for selected daily paths). There was no relationship between daily path length and the proportion of A. senegal, $H$. thebaica and T. cistoides in the baboons' feeding records. 
Table 3. Contribution (\%) of top 16 plant species to monthly feeding records

\begin{tabular}{|c|c|c|c|c|c|c|c|c|c|c|c|}
\hline & March & April & May & June & July & Aug & Oct & Nov & Dec & Jan & Feb \\
\hline Acacia senegal & 15.6 & 20.3 & 23.5 & 40.3 & 24.8 & 21.0 & 21.6 & 26.1 & 17.1 & 16.0 & 32.6 \\
\hline Hyphaene thebaica & 48.4 & 24.9 & 25.2 & 19.7 & 8.2 & - & 5.3 & 4.5 & 33.2 & 32.3 & 31.6 \\
\hline Tribulus cistoides & 4.9 & 3.3 & 5.5 & 0.3 & 10.9 & 59.4 & 16.6 & 5.5 & 3.1 & 1.1 & 0.9 \\
\hline Acacia nubica & - & 4.1 & 8.8 & 6.0 & 6.5 & 7.9 & 18.3 & 15.8 & 3.1 & 1.7 & 5.2 \\
\hline Pentarrhinum insipidum & 0.8 & - & 0.4 & 1.7 & 15.7 & 1.3 & 5.0 & 6.1 & 3.4 & 10.5 & 4.7 \\
\hline Acacia tortilis & 2.5 & 3.0 & 2.6 & 2.9 & 2.4 & 1.6 & 0.3 & 4.2 & 11.8 & 12.7 & 4.7 \\
\hline Acacia mellifera & 3.2 & 1.1 & 3.4 & 0.6 & 7.1 & 0.3 & 4.7 & 4.6 & 2.6 & 1.9 & 1.4 \\
\hline Typha latifolia & 1.6 & 3.8 & 0.9 & 3.1 & - & - & 1.0 & 1.9 & 4.4 & 4.4 & 2.8 \\
\hline Sporobolus spicatus & - & 3.8 & 5.0 & 7.4 & 1.4 & 0.3 & 3.0 & 1.0 & 1.4 & 0.3 & - \\
\hline Salvadora persica & - & 1.1 & 1.1 & 0.3 & 0.7 & - & - & 1.6 & 5.3 & 2.5 & 7.6 \\
\hline Balanites aegyptiaca & - & 1.4 & - & 0.9 & 1.0 & - & 2.3 & 3.9 & 2.9 & 3.0 & 2.8 \\
\hline Seddera bagshewi & - & 8.5 & 1.5 & 1.1 & 0.3 & 2.2 & 3.0 & 1.9 & 0.6 & - & 0.5 \\
\hline \multicolumn{12}{|l|}{ Psilotrichum } \\
\hline gnaphalobryum & 2.5 & 6.9 & - & - & - & - & - & 8.0 & 1.4 & - & - \\
\hline Cyperus rotundus & 1.6 & 3.8 & 2.9 & 1.1 & 0.3 & - & 1.7 & 1.0 & 3.2 & - & - \\
\hline Grewia erythreae & 0.8 & 1.1 & 1.3 & 4.6 & 4.4 & - & 0.3 & - & - & - & - \\
\hline Barleria spinisepala & - & - & 2.4 & 1.1 & 1.0 & - & 4.3 & 2.3 & - & - & - \\
\hline
\end{tabular}

\section{Discussion}

Feeding Ecology

Over the study period, band 1 at Filoha fed most frequently on the fruit of $H$. thebaica, and the seeds, leaves and flowers of $A$. senegal. The top 3 plant species comprised more than half of the baboons' annual feeding budget. There was, however, considerable monthly variation in the feeding behavior of band 1 (table 3 ), and the baboons were selective feeders. As predicted, the baboons fed predominantly on $H$. thebaica when its fruit was available and preferred the flowers of $A$. senegal to its leaves (fig. 3). The diet of hamadryas baboons at Filoha was first quantified in 20012002 [Swedell et al., 2008], with a focus on band 3. Similar to the 40 plant species that band 1 consumed in the current study, 44 plant species contributed to the diet of band 3 . As with band 1, the top 2 species in the diet of band 3 were $H$. thebaica and A. senegal, and all 12 plant species that contributed at least $1 \%$ to the diet of band 3 also contributed at least $1 \%$ to the feeding budget of band 1 . Band 3 spent almost half its feeding time (47.4\%) eating $H$. thebaica, however, and $11.6 \%$ of feeding time on $A$. senegal, compared to 21.2 and $23.5 \%$, respectively, for band 1 in the current study. Band 3 also relied more heavily on Typha latifolia and Cyperus spp. than did band 1 . These disparities in diet may reflect differences in the home ranges of band 1 and band 3 [Schreier and Swedell, 2008]; a higher percentage of the home range of band 3 consists of palm forests and swamp vegetation, compared to that of band 1 . It is also possible that interannual variation in fruit availability accounts for the difference in palm fruit consumption across the 2 study periods; since phenology was not moni- 
tored in 2001-2002, however, we cannot test this possibility. Differences in sampling regimes may also explain different results in the 2 studies. In 2001-2002, data were collected during 10-min focal samples of adult males, while in the current study data were collected on both males and females via scan sampling. Furthermore, data collection in 2001-2002 occurred during one 4- to 6-day session each month, whereas I collected data throughout each month in this study.

\section{Ranging Patterns}

The mean daily path length of band 1 of $8.3 \mathrm{~km}$ (range $=4.6-14.2 \mathrm{~km}, \mathrm{n}=105)$ is slightly longer than the $7.5 \mathrm{~km}$ reported for band 1 in 1996-1998 $(\mathrm{n}=27)$ [Swedell, 2002b, 2006]. At Awash Station, Ethiopia, the mean daily path length was $6.5 \mathrm{~km}$ $(\mathrm{n}=7)$ [Nagel, 1973], while the mean daily path length at Erer Gota was $13.2 \mathrm{~km}$ (range $=4.1-19.2, \mathrm{n}=9$ ) [Kummer, 1968]. The daily path lengths of band 1 are comparable to those reported by Sigg and Stolba [1981] at Erer Gota: $8.6 \mathrm{~km}$ for band 1 $(\mathrm{n}=57)$ and 10.4 for band $2(\mathrm{n}=13)$. Daily paths ranged from 1.04 to $14.03 \mathrm{~km}$ in Saudi Arabia, but no mean was reported [Biquand et al., 1992; Boug et al., 1994]. It should be noted that my results are most similar to those of Sigg and Stolba [1981], the study with the largest sample size. The other studies' smaller samples are probably not large enough to provide valid estimates of mean daily path length. Thus, contrary to expectations, despite the differences in resource distribution and availability between these typical hamadryas sites and Filoha, the daily path lengths of band 1 were not notably shorter than those in other hamadryas populations.

The fact that the daily path lengths of band 1 are comparable to those at other sites despite the presence, and high consumption, of doum palm fruit at Filoha may be a consequence of its large band size. While band 1 at Filoha consists of approximately 200 baboons and band 3 of about 400 baboons [Swedell 2002b, 2006; Schreier and Swedell, 2008], band sizes at other hamadryas sites ranged from 30 to 100 individuals (Erer Gota, Ethiopia [Kummer, 1968; Sigg and Stolba, 1981; Abegglen, 1984]; Awash River, Ethiopia [Nagel, 1973]; Saudi Arabia [Kummer et al., 1981; Biquand et al., 1992]; Yemen [Al-Safadi, 1994]). An increase in group size is expected to increase the distance group members must travel each day in order to meet their energetic and nutritional requirements [Eisenberg et al., 1972; Altmann, 1974; Chapman and Chapman, 2000], and thus comparisons of daily path lengths across sites with different band sizes may obscure the role that palm fruit plays on ranging patterns at Filoha.

Despite the mean daily path length being comparable to that at other hamadryas sites, and the lack of a clear relationship between monthly mean daily path length and the proportion of the most commonly consumed food species in monthly feeding budgets, the baboons' ranging behavior did seem to be impacted by feeding behavior and food availability. Specifically, home range use appeared to reflect where the baboons fed on doum palm fruit. In March, April and May, the baboons fed on palm fruit most regularly from the Hot Springs and Alibete palm forests when fruit abundance was at its peak (fig. 4). In fact, band 1 traveled to one of these palm forests during each of its travel routes during these 3 months (fig. 5). By mid-June almost no palm fruit was available in palm forests, and the band shifted its use of the home range to the south and fed on palm fruit mostly from the palm clumps southeast of Filoha. The baboons consumed very little palm fruit in July, August, October and November. When they resumed eating palm fruit regularly again in December, 
they did so mainly from the palm clumps southeast of Filoha. The same was true in January and February, although by this time the baboons began to return to the Hot Springs and Alibete palm forests as fruit became available.

Furthermore, I observed the baboons eating palm fruit on 83 of the 105 days for which I have complete travel routes. On at least two thirds of these routes $(n=56)$, the farthest point from the evening sleeping site was located in a palm forest or palm clump. Sites in the Hot Springs palm forest were the farthest points in the baboons' travel routes at least 23 times, and palm clumps southeast of Filoha marked the farthest point from the evening sleeping site on at least 20 days. The Alibete palm forest contained the farthest point at least 8 times, and the palm clumps $3 \mathrm{~km}$ northwest of the Filoha cliff sleeping site were farthest from the sleeping site on at least 5 days. In addition to influencing where the baboons range, therefore, their reliance on palm fruit also appears to play a role in determining daily path lengths.

In August when T. cistoides flowers made up the bulk of the diet of band 1, the baboons ranged in the Wasaro region the entire month. On 6 of the 9 complete daily paths, the baboons remained exclusively on the west side of the Wasaro cliff, despite the fact that these flowers were available throughout their home range during this wet season month. The baboons may have restricted their ranging area during this time to take advantage of the limited time period during the year when both a preferred food resource and water were available at Wasaro. Further investigation of the distribution, phenology and nutritional content of T. cistoides, particularly its flowers, is necessary to understand better the baboons' reliance on this species during the wet season.

Conclusions from this study should be taken with caution, however, due to limitations of the data set. First, the study period of 1 year is likely not long enough to fully characterize baboon diets [Norton et al., 1987; Swedell et al., 2008]. Second, an element of bias likely exists in the data. The large band size prohibited sampling every adult individual during band scans, and thus a food species was recorded just once regardless of how many individuals were eating it. It is possible, then, that commonly eaten foods are under-represented, and rarely eaten foods are over-represented, as a frequently consumed food counted as much as an uncommon food even if, say, 50 baboons were feeding on the former and only 1 on the latter. Furthermore, more systematic phenological sampling of doum palm fruit and A. senegal would have improved this study (e.g. sampling twice a month instead of monthly, monitoring plant parts underneath trees, additional sampling in Acacia patches not regularly used by the baboons to provide a more complete picture of the relationships between food availability and consumption and ranging). The phenology of T. cistoides was not quantified, and based on the important role this species appears to play on the baboons' feeding and ranging behavior during the wet season, systematic monitoring of the abundance of its plant parts might allow a greater understanding of its use.

\section{Conclusions}

In summary, hamadryas baboons at Filoha fed predominantly on doum palm fruit and the flowers, seeds and leaves of $A$. senegal. As predicted, the baboons focused on doum palms when its fruit was available and preferred the flowers of $A$. 
senegal when both flowers and leaves were available, indicating preference in food selection. Contrary to expectations, there were no clear relationships between daily path length and the proportion of these food species in the baboons' diet, and the mean daily path length at Filoha was not significantly shorter than that at other sites despite the presence of doum palm fruit. However, group size may conceal the role of doum palm fruit in the baboons' ranging at Filoha: band 1 is at least twice as large as bands at other hamadryas sites yet still traveled similar distances each day. The distribution and availability of palm fruit was tied to where the baboons fed on palm fruit; the baboons utilized the northern part of their home range when they foraged in palm forests and they used the southern portion of their home range when they fed from the palm clumps southeast of Filoha.

\section{Acknowledgments}

I thank Larissa Swedell for help at all stages of the project as well as for funding. I also thank the Wildlife Conservation Department of Ethiopia for permission to conduct research at Filoha. Funding was provided by the City University of New York PSC-CUNY Research Award Program (award No. 66588-0035 to L. Swedell), the New York Consortium in Evolutionary Primatology and the City University of New York PhD Program in Anthropology. I thank Getenet Hailemeskel for help identifying plant species at Filoha, and Getenet Hailemeskel, Christine Tuiallon and Matt Klein for help conducting vegetation transects. For logistical support in the field, I thank Demekech Woldearegay, Teklu Tesfaye, Getu Mamush, Denberu Tesfaye and Getu Kifle. Thanks to Carl J. Terranova for providing valuable feedback on an earlier version of the manuscript.

\section{References}

Abegglen JJ (1984). On Socialization in Hamadryas Baboons. London, Associated University Press.

Al-Safadi MM (1994). The hamadryas baboon, Papio hamadryas (Linnaeus, 1758) in Yemen (Mammalia: Primates: Cercopithecidae). Zoology in the Middle East 10: 5-16.

Altmann SA (1974). Baboons, space, time, and energy. American Zoologist 14: 221-248.

Altmann SA, Altmann J (1970). Baboon Ecology. Chicago, University of Chicago Press.

-Altmann SA, Post D, Klein DF (1987). Nutrients and toxins of plants in Amboseli, Kenya. African Journal of Ecology 25: 279-293.

Biquand S, Biquand-Guyot V, Boug A, Gautier J-P (1992). Group composition in wild and commensal hamadryas baboons: a comparative study in Saudi Arabia. International Journal of Primatology 13: $533-543$.

Boug A, Biquand S, Biquand-Guyot V, Kamal K (1994). Home range and daily march of commensal Papio hamadryas in the Alhada Mountain of Saudi Arabia. Congress of the International Primatological Society 15: 148.

Chapman CA, Chapman LJ (2000). Determinants of group size in primates: the importance of travel costs. In On the Move: How and Why Animals Travel in Groups (Boinski S, Garber PA, eds.), pp 24-42. Chicago, University of Chicago Press.

Chapman CA, Wrangham R, Chapman LJ (1994). Indices of habitat-wide fruit abundance in tropical forests. Biotropica 26: 160-171.

Cunningham E (2003). The Use of Memory in Pithecia pithecia's Foraging Strategies. PhD thesis, City University of New York.

Dunbar RIM (1988). Primate Social Systems. Ithaca, Comstock Publishing Associates.

- Dunbar RIM (1992). Time: a hidden constraint on the behavioural ecology of baboons. Behavioral Ecology and Sociobiology 31: 35-49.

Dunbar RIM (1996). Determinants of group size in primates: a general model. In Evolution of Social Behaviour Patterns in Primates and Man (Runciman WG, Maynard Smith J, Dunbar RIM, eds.), pp 33-57. Oxford, Oxford University Press.

Eisenberg JF, Muckenhirn NA, Rudran R (1972). The relation between ecology and social structure in primates. Science 176: 863-874. 
Hill RA (1999). Ecological and Demographic Determinants of Time Budgets in Baboons: Implications for Cross-Populational Models of Baboon Socioecology. PhD thesis, University of Liverpool.

-Hill RA, Dunbar RIM (2002). Climatic determinants of diet and foraging behaviour in baboons. Evolutionary Ecology 16: 579-593.

Kummer H (1968). Social Organization of Hamadryas Baboons: A Field Study. Chicago, University of Chicago Press.

Kummer H (1971). Primate Societies: Group Techniques of Ecological Adaptation. Arlington Heights, Harlan Davidson.

Kummer H (1995). In Quest of the Sacred Baboon: A Scientist's Journey. Princeton, Princeton University Press.

Kummer H, Banaja AA, Abo-Khatwa AN, Ghandour AM (1981). Mammals of Saudi Arabia: Primates: a survey of hamadryas baboons in Saudi Arabia. Fauna of Saudi Arabia 3: 441-471.

Nagel U (1973). A comparison of anubis baboons, hamadryas baboons and their hybrids at a species border in Ethiopia. Folia Primatologica 19: 104-165.

Norton PM, Rhine RJ, Wynn GW, Wynn RD (1987). Baboon diet: a five-year study of stability and variability of the plant feeding and habitat of the yellow baboons (Papio cynocephalus) of Mikumi National Park, Tanzania. Folia Primatologica 48: 78-120.

- Peres CA (1994). Primate responses to phenological changes in an Amazonian terra firme forest. Biotropica 26: 98-112.

Schreier AL (2009). The Influence of Resource Distribution on the Social Structure and Travel Patterns of Wild Hamadryas Baboons (Papio hamadryas) in Filoha, Awash National Park, Ethiopia. PhD thesis, City University of New York.

-Schreier AL, Swedell L (2008). Use of palm trees as a sleeping site by hamadryas baboons (Papio hamadryas hamadryas) in Ethiopia. American Journal of Primatology 70: 107-113.

Schreier AL, Swedell L (2009). The fourth level of social structure in a multi-level society: ecological and social functions of clans in hamadryas baboons. American Journal of Primatology 71: 948-955.

Sigg H, Stolba A (1981). Home range and daily march in a hamadryas baboon troop. Folia Primatologica $26: 40-75$.

Swedell L (2002a). Affiliation among females in wild hamadryas baboons (Papio hamadryas hamadryas). International Journal of Primatology 23: 1205-1226.

Swedell L (2002b). Ranging behavior, group size and behavioral flexibility in Ethiopian hamadryas baboons (Papio hamadryas hamadryas). Folia Primatologica 73: 95-103.

Swedell L (2006). Strategies of Sex and Survival in Hamadryas Baboons: Through a Female Lens. Upper Saddle River, Prentice Hall College Division.

Swedell L, Tesfaye T (2003). Infant mortality after takeovers in wild Ethiopian hamadryas baboons. American Journal of Primatology 60: 113-118.

Swedell L, Hailemeskel G, Schreier A (2008). Composition and seasonality of diet in adult male hamadryas baboons: preliminary findings from Filoha. Folia Primatologica 79: 476-490.

Zinner D, Peláez F, Torkler F (2001). Distribution and habitat associations of baboons (Papio hamadryas) in Central Eritrea. International Journal of Primatology 22: 397-413. 